\title{
Writing about Literature: A Guide for the Student Critic
}

\author{
Jaclyn Rea \\ Simon Fraser University
}

W.F. Garrett-Petts, Writing about Literature: A Guide for the Student Critic, Peterborough, Ontario: Broadview Press, 2000. 141 pages.

Although Writing about Literature may seem too discipline-specific to be of practical use to those who teach writing outside of literary studies, Garrett-Petts' approach to the teaching of composition provides us with another occasion to think about the historical, social and critical contexts that inform writing practice and the teaching of writing in our respective fields. As Garrett-Petts suggests, left unexamined, these contexts have a tendency to preserve the mystery that surrounds writing in the disciplines, thereby safeguarding the privileged status of insider knowledge and sustaining instruction based on models of tacit or failed acquisition. Drawing on recent research in genre theory, the author aims to dispel some of this mystery. Part rhetoric, part casebook, Writing about Literature is meant as "an insider's guide to the language, issues, approaches, styles, assumptions, and traditions that inform the writing of successful critical essays" (11).

Garrett-Petts' intent, then, is to help students think and write like professionals in the discipline, to help them understand that successful writing in literary studies involves an awareness of the things that shape this discipline's ways of thinking, talking and writing. Attempting to go beyond conventional handbook advice, GarrettPetts offers students a number of ways to understand and engage in the discursive practices of the discipline: a brief history of writing in English Studies and the rhetorical traditions that inform this writing; a discussion of the field's concerns, approaches and valued topoi; exemplary models of student and professional essays addressing the same short story; exercises meant to engage students in the critical conversation and to elicit an understanding of this conversation; and commentary from professional writers in the field. 
So, this book will be of interest to those curious about the ways a genre theory approach can explain how rhetorical contexts shape writing expectations in a particular discipline. Yet, those seeking a more sophisticated analysis of the ways context informs the style or language of the genre of literary criticism will be disappointed, will find that matters of style and language are absorbed into the discipline's preoccupation with reading rather than highlighted as indices of discursive practice. In spite of Garrett-Petts' observation that there is a propensity among teachers in the field to teach "reading without writing" (6), to teach literature as "ritual, self-discovery, aesthetic involvement, and textual interpretation" ( $(7)$, his own focus on strategies to help students generate a critical reading, in the absence of a genre-based stylistic analysis, may end up itself preserving the mystery that surrounds language use in and for specific contexts.

The author begins with the now familiar premise that writing is rhetorical and, as rhetorical, must attend to such things as purpose, audience and context. However, Garrett-Petts characterizes purpose as one's own purpose. He therefore directs students to note their personal responses and intentions regarding the work under study. And he suggests that students locate this purpose by attending to those places in the text which disrupt their values and experiences, places which later will help them develop questions or topics for their papers and which will "encourage [them] to see the world and [them] selves from a new or different perspective" (21). In this return to a more conventional account of bringing one's personal experience to the reading of literature, very little is said, in the beginning sections of this textbook, about the rhetorical purpose of the critical essay itself or its purpose's relation to the audience and context of this genre. Instead, much is implied about literature's capacity to unsettle and thus cultivate a particular set of distinctions or knowledges about the self and the world that, in earlier incarnations of literary studies, operated as a means of reinforcing or instilling 'appropriate' forms of thought and behaviour. While GarrettPetts notes that "English Studies began in the universities as a means of inculcating 'educated' taste, judgement, and aesthetic norms" (9), the expressivist approach that frames the author's discussion of writing in this discipline may end up becoming a means to regulate social conscience, to identify and correct the values, attitudes and sensibilities expressed by first year students in their reading and writing (cf. Ian Hunter, Culture and Government: The Emergence of Literary Education, 1988).

Much in this textbook, however, does encourage students to move beyond their personal responses. Drawing on Richard Beach and Susan Hynds' strategies for developing new discourse practices, Garrett-Petts details four learning stances meant to help students understand the larger critical conversation within English Studies: 1. the social stance, which involves an awareness of how ideas are generated in class- 
room discussion and an awareness of this discussion's patterns of response and specialized vocabulary; 2 . the textual stance, which provides students with an opportunity to focus on textual features (of the texts under study) and on writing conventions (of the texts they will produce); 3 . the institutional stance, which requires an understanding of the university's premises, conventions, goals, ways it organizes knowledge, and its use of language; and 4. the field stance, which involves an analysis of the theoretical approaches, language, values, assumptions and issues that inform critical practice in the discipline. To further develop students' understanding of the field stance, Garrett-Petts draws on the work of Jeanne Fahnestock and Marie Secor, who outline the topoi, the available means or modes of persuasion, most valued in English Studies. (These include assumptions about, and thus consistent critical focus on, literature's "inherent" complexity, its ambiguity and its contradictoriness.) As strategies to help students focus or organize their own interpretations of literature, these field specific topoi provide students with useful information about the shared assumptions that define this discourse community and help shape its critical concerns and methods.

As a rhetoric of criticism, then, Writing about Literature will certainly familiarize students with the traditions and concerns that inform writing practice in the field. Indeed, students should come away from this text with a better understanding of why we in the discipline do what we do (5). Yet, as a critical casebook, one that purports to offer advice about writing a "well-crafted and critically informed essay" (5), this textbook falls short in its explanations of how we do what we do. Although there is plenty of good advice meant to help students generate a successful reading of literature, commentary about style and language hovers just out of sight. For example, although Garrett-Petts briefly comments on the topographical appearance of the critical essay ("The critical essay in English is full of quotations"; "English encourages much more direct quotation and discussion of those quotations" [58]), matters of style and language are, for the most part, left up to the student to sort out. In exercises meant to encourage discussion about the model essays in the textbook, students are required to answer such questions as:

How does [the author] situate her reading as part of an ongoing critical discussion? What is the function of phrases such as "indeed," in fine," [sic] "after all," and "of course"? Look especially at how [the author] uses transitions to link ideas. Can you identify two or three linking devices? (102) 
Do you find [the author's] use of the personal pronoun ("I") effective? (109)

Here, an analysis of the style of these models (e.g. their use of reported speech, markers of obviousness, relevance/coherence patterns, use of discursive " $I$ ") could have provided students with helpful information about the ways style reflects and guides practice (cf. Giltrow's Academic Writing: Writing and Reading across the Disciplines, 1995). Instead students (and instructors) are left to decipher the effectiveness of such stylistic expressions without fully understanding their rhetorical functions, the ways in which these expressions themselves are informed by social, historical and institutional contexts. Moreover, the commentary from professionals in the field reinforces the emphasis on reading, on the process of generating an interpretation (e.g. on theoretical frameworks, ways to generate topic). When these professionals do discuss the activity of writing, they provide commonplace advice to note-take, draft and revise - sound advice, but advice that, without other kinds of discursive analysis, tends to shelter the assumptions and values embedded in the writing of this discipline, the tacit know-how of professionals in the field.

Still, Garrett-Petts' Writing about Literature is a landmark publication in the history of handbooks with similar titles. As the first handbook of its kind to employ a genre theory perspective, it heralds a long overdue consideration of the specificity of the contexts and concerns which inform writing in this discipline. The strength of this book, then, lies in its insights into these contexts and concerns, insights which promise more informed practice for both students and instructors. 